\title{
Risk for Severe Pulmonary Tuberculosis among Alcoholics and Diabetics
}

\author{
Balachandran $\mathbf{J}^{1}$,Sreekumar $\mathbf{B}^{2}$ \\ ${ }^{1}$ Associate Professor of Pulmonary Medicine, ${ }^{2}$ Professor of Biochemistry,Travancore Medical College, Kollam-691589
}

\section{Abstract}

Tuberculosis is a major public health problem. Some patients present with minimal lesions where as others present with advanced lesions. Patients with advanced or severe disease have high morbidity and mortality. Their infectiousness is also high. This is a Case control study to identify the strength of associations between two important factors, namely alcoholism and diabetes mellitus, and severity of disease. There were 80 cases and 80 controls. Cases were patients with severe disease and controls were patients with minimal disease. Severity of tuberculosis was assessed by chest radiographic criteria as per American Thoracic Society recommendation. The study was done over a period of 18 months. Both inclusion and exclusion criteria were applied in the selection of cases and controls. $46.25 \%$ of cases and $23.75 \%$ of controls were alcoholic. $15 \%$ of cases were suffering from diabetes mellitus whereas only $5 \%$ of controls were diabetic. Univariate analysis showed that both alcoholism and diabetes mellitus were significant risk factors. When the confounding effect of age was also taken into account, diabetes mellitus was not found to be a significant risk factor in causing severe pulmonary tuberculosis. Therefore preventive measures may be targeted to alcoholics for the early identification of severe pulmonary tuberculosis.

Key Words:Pulmonary tuberculosis, severe disease, risk factors, alcoholism, diabetes mellitus

\section{INTRODUCTION}

$\mathrm{T}$ uberculosis is a significant cause of morbidity and mortality especially of the developing world.[1] In about $90 \%$ of cases[2], the disease involves the lungs. The development of pulmonary tuberculosis from its onset to its various clinical manifestations is dependent on the various aspects of cell mediated immunity including delayed hypersensitivity. The inhaled bacillus may multiply or it may be eliminated by alveolar macrophages before any lesion is produced. The interaction between bacillary multiplication and the response of the host to their components determines whether the infection will progress or regress, and if it does progress, what form will it take.[3] Tuberculosis is a local disease in that each lesion is handled by the host almost as if other lesions do not exist. Thus lesions in one area may progress, while those in other areas may stabilize or even regress. [4] The liquefaction of caseous foci increases the infectiousness of pulmonary tuberculosis among the human population because it results in cavity formation. A cavity is formed when a caseous focus ruptures through the wall of a nearby bronchus and discharges its contents into the air passages. The extent of the disease is determined by the number of bacilli and their viability in addition to the amount of aspiration of liquefied caseous material through the bronchial tree.[5] Tuberculosis is a granulomatous disease. Granuloma formation is due to delayed type hypersensitivity. Thus the host could overcome the reinfection/reactivation much more rapidly than it overcame the primary infection. But the delayed type hypersensitivity is not always beneficial. Such hypersensitivity is responsible for the tissue injury that occurs when the concentrations of bacilli and their products are high.[6] It is well known that serious infections appear to occur more frequently in alcoholic patients. Susceptibility of alcoholics to pulmonary tuberculosis is caused by alteration of immune function and mechanical defenses.[7] In many infections, mortality is increased in alcoholics with the course of the illness being more

\section{Address for correspondence*}

\section{Dr J Balachandran}

Associate Professor of Pulmonary Medicine

Travancore Medical College, Kollam

Mob: +91 9447397958

Email : doctorbalachandran@gmail.com severe and complications frequent. Prior to 1990, pulmonary tuberculosis was found in nearly $50 \%$ of autopsies on diabetic persons. Tuberculosis was found to be at least 2 times more frequent in diabetics than in the general population.[8] An Indian study has also observed this fact.[9] A study in Tanzanian subjects showed pulmonary tuberculosis to progress rapidly in patients with diabetes mellitus.[10] It was concluded that a high index of suspicion was required in diabetic patients. The present study was undertaken to find out whether alcoholism and diabetes mellitus are associated with increased risk of development of severe forms of pulmonary tuberculosis.

\section{MATERIALS AND METHODS}

Patients admitted in the wards of the Department of Pulmonary Medicine, Medical College, Trivandrum as well as in the wards of the Health services department, Pulayanarkottah Hospital, Trivandrum, who satisfied the inclusion and exclusion criteria were selected as cases. Controls were selected from patients attending the state TB centre, Trivandrum, satisfying the inclusion and exclusion criteria.

\section{Inclusion criteria for cases}

1. Sputum AFB positivity

2. "Far advanced lesions" in the chest x-ray as per ATS criteria

\section{Inclusion criteria for controls}

1. Sputum AFB positivity

2. "Minimal lesions" in the chest $\mathrm{x}$-ray as per ATS criteria

\section{Exclusion criteria}

1. History of Anti TB treatment for more than 10 days

2. Presence of radiological lesions in a previous radiograph, if available

The sample size was estimated to be 72 . Assuming an attrition rate of $10 \%, 80$ patients were included in the study as cases and 80 patients as controls.

The study was completed by 18 months. 


\section{RESULTS}

Table 1 - Alcoholic Habits of study population

\begin{tabular}{|l|l|l|l|l|l|}
\hline Sl No & Residence & Cases & \% of total & Controls & \% of total \\
\hline 1 & Alcoholics & 37 & 46.25 & 19 & 23.75 \\
\hline 2 & Non-Alcoholics & 43 & 53.75 & 61 & 76.25 \\
\hline & Total & 80 & 100 & 80 & 100 \\
\hline
\end{tabular}

Table 2 - Diabetes mellitus in study population

\begin{tabular}{|l|l|l|l|l|l|}
\hline Sl No & Diabetes mellitus & Cases & \% of total & Controls & \% of total \\
\hline 1 & Present & 12 & 15 & 04 & 5 \\
\hline 2 & Not present & 68 & 85 & 76 & 95 \\
\hline & Total & 80 & 100 & 80 & 100 \\
\hline
\end{tabular}

Table 3 - Relative risk of patients with history of Alcoholism in severe disease compared to minimal disease

\begin{tabular}{|l|l|l|l|l|l|l|}
\hline coeff. & S.E. & Z-score & p-value & O.R. & Upper & Lower \\
\hline 1.0162 & 0.3454 & 2.9419 & 0.0033 & 2.763 & 1.404 & 5.437 \\
\hline
\end{tabular}

Table 4 - Relative risk of Diabetes mellitus in severe disease compared to minimal disease

\begin{tabular}{|l|l|l|l|l|l|l|}
\hline coeff. & S.E. & Z-score & p-value & O.R. & Upper & Lower \\
\hline 1.2098 & 0.6010 & 2.0131 & 0.0441 & 3.353 & 1.032 & 10.889 \\
\hline
\end{tabular}

Table 5 - Relative risk of Age and Alcoholism when these two variables were considered together

\begin{tabular}{|l|l|l|l|l|l|l|l|}
\hline Term & coeff. & S.E & Z-score & p-value & O.R & Lower & Upper \\
\hline Age & .0315 & .0119 & 2.6329 & .0085 & 1.032 & 1.008 & 1.056 \\
\hline Alcoholism & .7771 & .3569 & 2.1777 & .0294 & 2.175 & 1.081 & 4.378 \\
\hline
\end{tabular}

Table 6 - Relative risks of Age and Diabetes mellitus when these two variables are considered together

\begin{tabular}{|l|l|l|l|l|l|l|l|}
\hline Term & coeff. & S.E. & Z-score & p-value & O.R. & Lower & Upper \\
\hline Age & .0346 & .0117 & 2.9495 & .0032 & 1.035 & 1.012 & 1.059 \\
\hline DM & 1.0543 & .6100 & 1.7284 & .0839 & 2.870 & 1.868 & 9.486 \\
\hline
\end{tabular}

Diabetes mellitus is not found to be a significant risk factor when age is also taken into account. This is probably because the number of Diabetes in the younger age group was not sufficient for statistical analysis.

\section{DISCUSSION}

Pulmonary tuberculosis is characterised by cavity formation especially in its severe forms of the disease[11]. If extensive and bilateral, these increase the mortality and morbidity of the host. In addition the disease also becomes more infectious and hence the significance of these severe forms of pulmonary tuberculosis.[12] The gold standard of diagnosis of pulmonary tuberculosis is sputum examination for acid fast bacilli[2,13]. The severity is assessed by radiological criteria as per ATS recommendation[14]. Why some patients present with severe forms of pulmonary tuberculosis has not clearly been answered. Most of studies point to the risk of development of tuberculous infection and disease and not on severity[7-10]. The present study tries to find out whether alcoholism and diabetes mellitus are independent risk factors for the development of severe forms of pulmonary tuberculosis. The data was analysed and multiple logistic regression was performed by unconditional and conditional methods. Univariate analysis was done first and Z-score as well as Odds Ratio were calculated for each variable. In the multivariate analysis, two variables were analysed together. The confounding effect of one variable over another was also looked for.

Univariate analysis: By univariate analysis(tables 3 and 4), both alcoholism $(\mathrm{p}$ value $=0.0033)$ and diabetes mellitus( $\mathrm{p}$ value $=0.0441$ ) were found to be risk factors for the development of severe form of pulmonary tuberculosis.

Multivariate analysis: Analysis was done considering more than one variable in each step. This also helped to identify the confounding factors. When alcoholism and age were analysed together (table 5), alcoholism was found to be a significant risk factor independent of age $(p$ value $=0.0294)$. When diabetes mellitus and age were analysed by multivariate method (table 6), diabetes mellitus was not found to be significant ( $\mathrm{p}$ value $=$ $0.0839)$

\section{CONCLUSION}

This study was done to find out whether there was any significant risk for the development of severe forms of pulmonary tuberculosis in alcoholics and in diabetics compared to nonalcoholics and non-diabetics respectively. Both were found to be significant risk factors by univariate analysis. But when analysed by multivariate method, taking age also into account, only alcoholism was found to be a significant risk factor for the development of severe pulmonary tuberculosis. Thus alcoholics may be identified as high risk group for developing severe pulmonary tuberculosis. The reason for alcoholics having higher risk than non-alcoholics could be due to alteration of immune function and mechanical defences.

\section{REFERENCES}

1. World Health Organization (2009). "Epidemiology" .Global tuberculosis control: epidemiology, strategy, financing. pp. 6-33. Retrieved 12 November 2009.

2. Behera, D. (2010). Textbook of pulmonary medicine (2nd ed.). New Delhi: Jaypee Brothers Medical Publishers p. 457.

3. Dannenberg A M Jr (1984). Pathogenesis of Tuberculosis Microbiology p 344-354

4. Salvin S B and Neta R (1975). Relation between Delayed Hypersensitivity and Immunity in Tuberculosis. American Review of Respiratory Disease (111); 373-377

5. Kumar V, Abbas AK, Fausto N, Mitchell RN (2007). Robbins Basic Pathology (8th ed.). Saunders Elsevier. pp. 516-522.

6. Grosset J (2003). "Mycobacterium tuberculosis in the Extracellular Compartment: an Underestimated Adversary". Antimicrob Agents Chemother 47 (3): 833-6; 47.3.833836.2003.

7. Sternbach G L (1990) Infections in alcoholic patients. Medical clinics of North America 8(4); 793-803

8. Root HF. (1934)The association of diabetes and tuberculosis. NEng J Med 210:1-13.

9. Nanda CN, Tripathy SN.(1968) Association of diabetes mellitus with pulmonary tuberculosis. The Journal of the Association of Physicians of India. 1968;16(10):741-6.

10. Swai A B (1990) Tuberculosis in diabetic patients in Tanzania. Tropical Doctor 20(4); 147-150

11. Dannenberg A M Jr. and Sugimoto M (1976). Liquifaction of caseous foci in tuberculosis. American Review of Respiratory 
Disease (113);257-259

12. Wiesner B (1990) The causes of severe forms of tuberculosis. Pneumologie (44); 499-500

13. Jindal SK editor-in-chief (2011). Textbook of pulmonary and critical care medicine. New Delhi: Jaypee Brothers Medical Publishers. p. 544

14. American Review of Respiratory Disease "Diagnostic Standards and Classification of Tuberculosis." Vol. 142, No. 3, Sept 1990 pp. 725-735. 